\title{
Management of Hepatocellular Carcinoma in Japan as a World-Leading Model
}

\author{
Masatoshi Kudo \\ Department of Gastroenterology and Hepatology, Kindai University Faculty of Medicine, \\ Osaka-Sayama, Japan
}

\section{Introduction}

Prof. M. Kudo

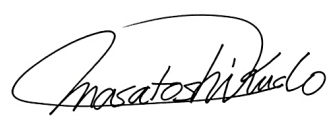

Editor Liver Cancer

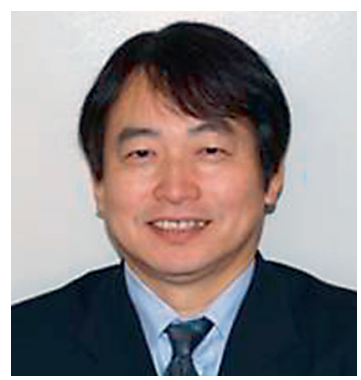

Japan has achieved highly favorable outcomes in hepatocellular carcinoma (HCC) treatment. Several factors contributed to this achievement as shown in Tables 1 and 2. The establishment of a nationwide liver cancer screening program, which was developed in the 1980s and involves institutes across all over Japan, is one of such factors. For example, Japan was the first country in the world to develop and implement diagnostic ultrasound systems for liver cancer screening. In addition to the already established tumor marker $\alpha$-fetoprotein (AFP), other markers such as protein induced by vitamin Kabsence or antagonist-II (PIVKA-II) and Lens culinaris-agglutinin-reactive fraction of AFP (AFP-L3) were developed in Japan. These two tumor markers were included among health insurance-covered screening tests in 1989 and 1994, respectively. Japan is the only country in the world in which these three tumor markers are included in routine surveillance under national health insurance without restrictions. Other important achievements in Japan include the invention of transcatheter arterial chemoembolization (TACE) [1], the development and the world's first commercialization of technetium-99m galactosyl human serum albumin liver scintigraphy for the assessment of hepatic functional reserve [2, 3], the world's first hepatectomy [4], the development of anatomic liver resection [5], and the invention of local ablation (percutaneous ethanol injection) [6] and percutaneous microwave coagulation therapy [7]. Japan also has the highest number of cases treated with radiofrequency ablation (RFA). Other methods developed in Japan include contrast-enhanced liver ultrasound (initially by intra-arterial 
Table 1. Epoch-making developments, which were established in Japan first in the world

1949 World 1st case of anatomical right liver lobectomy (Prof. Ichio Honjo, Kyoto Univ.)

1950 Development of ultrasound machine (Japan Radio, later ALOKA Company)

1967 Foundation of LCSGJ, started nationwide survey (Dept. Surgery, Kyoto Univ.)

1971 Development of ultrasound electronic scanner (ALOKA company)

1978 Invention of TAE for HCC (Prof. Ryusaku Yamada)

1982 Invention of contrast-enhanced US (arterial) (Yasuo Matsuda, Masatoshi Kudo)

1982 Invention of color Doppler flow imaging (ALOKA Company)

1983 Invention of CTHA/CTAP (Prof. Osamu Matsui)

1983 Invention of PEIT (percutaneous ethanol injection therapy) (Nobuyuki Sugiura)

1985 Establishment of anatomical liver resection (Prof. Masatoshi Makuuchi)

1990 Superselective cTACE (Profs. Hideo Uchida, Hironobu Nakamura, Osamu Matsui)

1990 Invention of microwave coagulation therapy (Prof. Toshihito Seki)

1989 Approval and reimbursement of PIVKA-II (Eisai Company)

1992 Development of asialoglycoprotein receptor scintigraphy, reimbursement (Masatoshi Kudo)

1992 Establishment of pathological concept of early HCC (Prof. Masamichi Kojiro)

1992 Invention of fusion imaging and strain elastography (Hitachi Company)

1992 Discovery of PD-1 molecule (Prof. Tasuku Honjo, Kyoto Univ.)

1994 Approval and reimbursement of AFP-L3 fraction (Wako Company)

1995 Stop HCC campaign for general citizen and general physician started by the Japan Society of Hepatology (JSH)

2004 Establishment of integrated staging system, JIS score (Masatoshi Kudo)

2007 Approval of Sonazoid (Dai-ichi Sankyo) invention of re-injection method (Masatoshi Kudo)

2014 Nivolumab approved for melanoma (Ono Pharma) (under trial in HCC)

2017 Lenvatinib (Eisai) (positive phase 3 global trial in HCC presented at ASC02017)

Table 2. Reasons why Japan established the world's best HCC practice system, different from other countries

Early HCC detection due to established nationwide surveillance

Free testing for HBsAg and HCV Ab anywhere in the clinic all over in Japan

Establishment of nationwide surveillance system by US and 3 tumor markers every $3-6$ months for high-risk patients for HCC

Measurement of all 3 tumor markers (AFP, PIVKA-II, AFP-L3) are covered by insurance

MDCT and/or EOB-MRI every 6-12 months/year for super high risk is also covered by insurance

Stop the HCC campaign for general citizen and physicians every year by JSH has been established

Antiviral therapy

Interferon treatment, interferon-free DAA treatment for hepatitis $\mathrm{C}$ and nucleoside analogue for hepatitis $\mathrm{B}$ are specially covered by the Government $(100-200$ USD/month can be paid by patients)

All of the patients only infected to hepatitis B or hepatitis $C$ can receive special reimbursement program

Establishment of precise diagnostic algorithm of HCC

Precise evaluation of intramodular hemodynamics by CTHA/CTAP or CEUS

Accurate pathological diagnosis, establishment of pathological diagnostic criteria of early HCC

Cooperative work between pathologist and clinician, image-pathology correlation

Skill of ultrasound diagnosis is superior to other country, ultrasound surveillance is easy since there are not many obese patients in Japan

Detection of very tiny nodule by extensive use of EOB-MRI and extensive effort on differential diagnosis between dysplastic nodule and early HCC leading to early treatment intervention

Unique US contrast agent, Sonazoid which have Kupffer phase makes it possible to accurate diagnosis and used as an accurate treatment guidance

Precise and accurate treatment selection and high quality treatment technique

Skill of resection, ablation, TACE and HAIC is better than other countries and outcome is best in the world Multimodal approach together with hepatologist, radiologist, surgeon, and oncologist of these treatments Especially hepatologist covers ablation, TACE, HAIC and systemic therapy as an organ specialist 


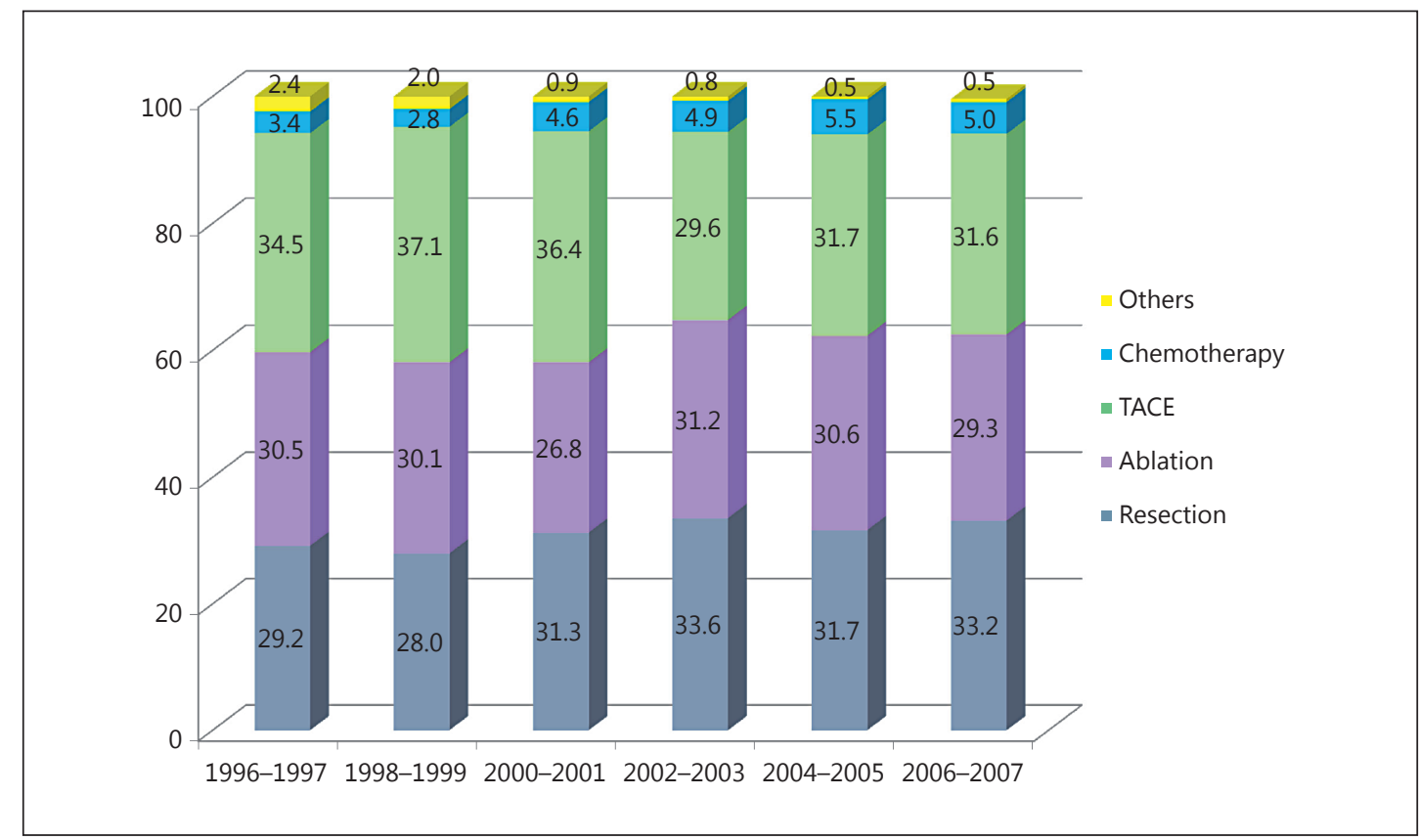

Fig. 1. Treatment modality for initially diagnosed HCC.

infusion of carbon dioxide microbubbles) [8, 9]; fusion imaging; perfluorobutane (Sonazoid), a unique ultrasound contrast agent that enables Kupffer-phase imaging; and defect reperfusion imaging using Sonazoid, which assists in screening, definitive diagnosis, and local ablation therapy [10].

Among several immunotherapies that garnered significant interest in recent years, PD-1 molecule was discovered by Prof. Tasuku Honjo of Kyoto University [11] and commercialized by Ono Pharmaceutical Co., Ltd. in Japan. A study investigating its use in the treatment of liver cancer is currently ongoing. Lenvatinib, a molecular-targeted agent discovered by Eisai Tsukuba Research Institute in Japan, was recently commercialized as an indication for thyroid cancer. The positive results of a trial that tested the efficacy of lenvatinib in liver cancer were reported at the 2017 annual meeting of the American Society of Clinical Oncology [12] followed by publication [13], and approval for this indication is currently pending.

Japan has made remarkable contributions to the screening, diagnosis, and treatment of liver cancer, and these have led to the best liver cancer treatment outcomes in the world. It is fair to say that the management of HCC in Japan sets a good example for the rest of the world, a fact acknowledged by HCC specialists globally.

\section{Results of a Follow-Up Survey of the Nationwide Registry of HCC Patients by the Liver Cancer Study Group of Japan}

In Japan, liver cancer screening by ultrasound and measurement of three tumor markers (AFP, PIVKA-II, and AFP-L3) is recommended every 3-4 months for super high-risk patients (cirrhosis caused by hepatitis B or hepatitis $C$ virus) or every 6 months for high-risk patients (hepatitis B, hepatitis C, and nonviral cirrhosis) [14, 15]. For super high-risk patients, multidetector-row computed tomography (MDCT) or gadolinium ethoxybenzyl diethylenetriamine pentaacetic acid magnetic resonance imaging (EOB-MRI) is recommended 1-2 times 


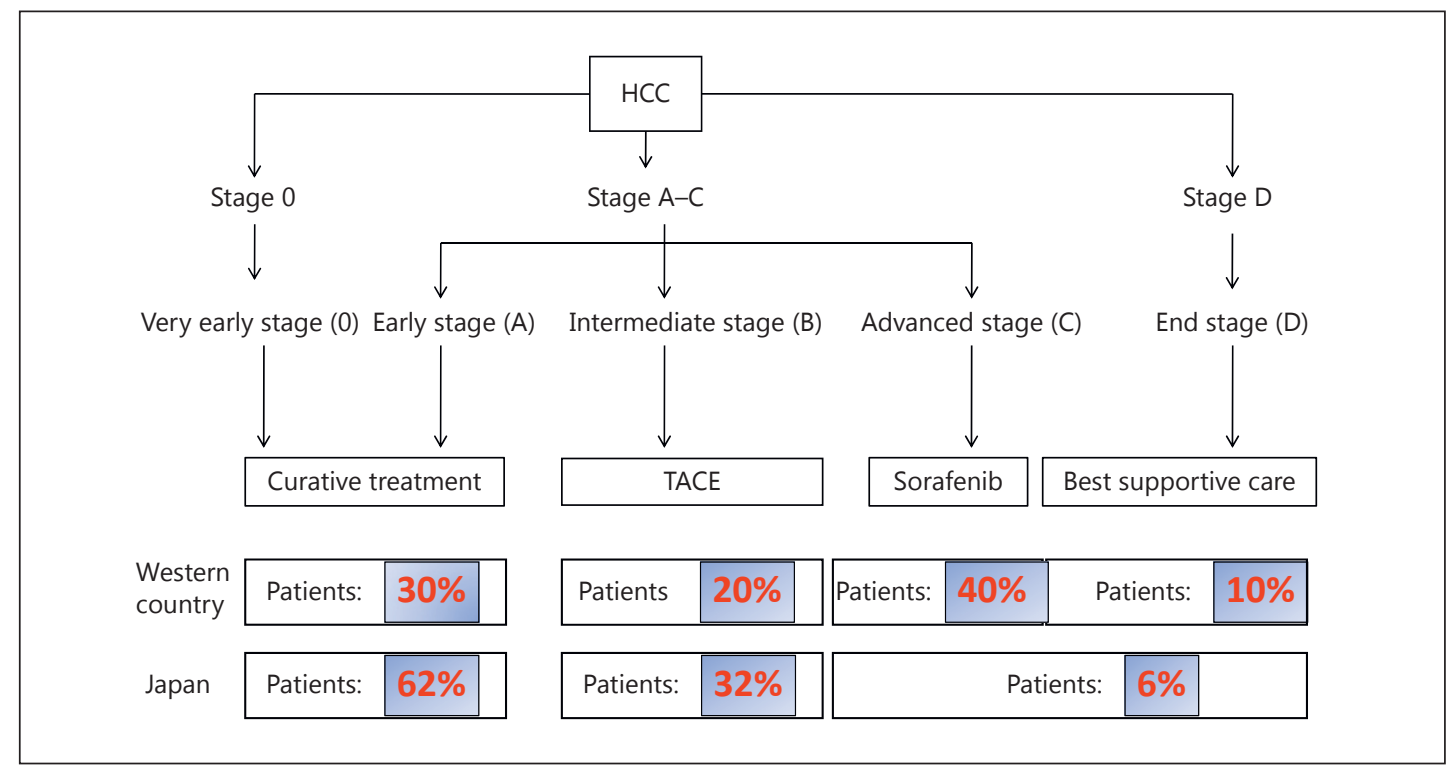

Fig. 2. BCLC stage at the initial detection of HCC: comparison between Western countries and Japan.

Table 3. Rate of BCLC 0 and A in various regions at the initial detection

\begin{tabular}{ll}
\hline Western countries & \\
Spain & $10-30 \%$ \\
Italy & $10-20 \%$ \\
United States & $17 \%$ \\
Latin America & $23 \%$ \\
Asian countries & \\
Japan & $60-65 \%$ \\
South Korea & $20-30 \%$ \\
Taiwan & $10-20 \%$ \\
China & $<10 \%$ \\
Other Asian countries & $<5 \%$ \\
\hline
\end{tabular}

per year. Because of these comprehensive surveillance programs, of all cases at the initial diagnosis, 62.5\% are curatively treatable early-stage HCC (Barcelona Clinic Liver Cancer [BCLC] stage 0 or $A$ ) that are treated by resection or RFA, 31.6\% are intermediate-stage liver cancer and are treated by TACE (Fig. 1), and only $6 \%$ of cases are advanced HCC with vascular invasion or extrahepatic spread (BCLC stage C) or Child-Pugh grade C HCC (BCLC stage D) [16]. This is completely different from the status in Western countries, where $50 \%$ of cases are BCLC stage C or D at first detection, which corresponds to the average HCC population based on conventional BCLC staging (Fig. 2). These differences reflect the efficacy and advanced status of the HCC surveillance program in Japan. This system appears to be unique to Japan because the detection rates of curatively treatable HCC (BCLC stages 0-A) do not exceed $30 \%$ in other parts of Asia or in Western countries (Table 3), which could be attributed to the lack of established nationwide surveillance programs. This highlights the value of the established HCC surveillance program in Japan.

In the early 1980s, the HCC screening system in Japan was not as effective as the present system because of the limited capabilities of diagnostic imaging tools. Consequently, the 5-year survival rate and median survival time were unsatisfactory. Between 1978 and 1982, 
Kudo et al.: Management of Hepatocellular Carcinoma in Japan as a World-Leading Model

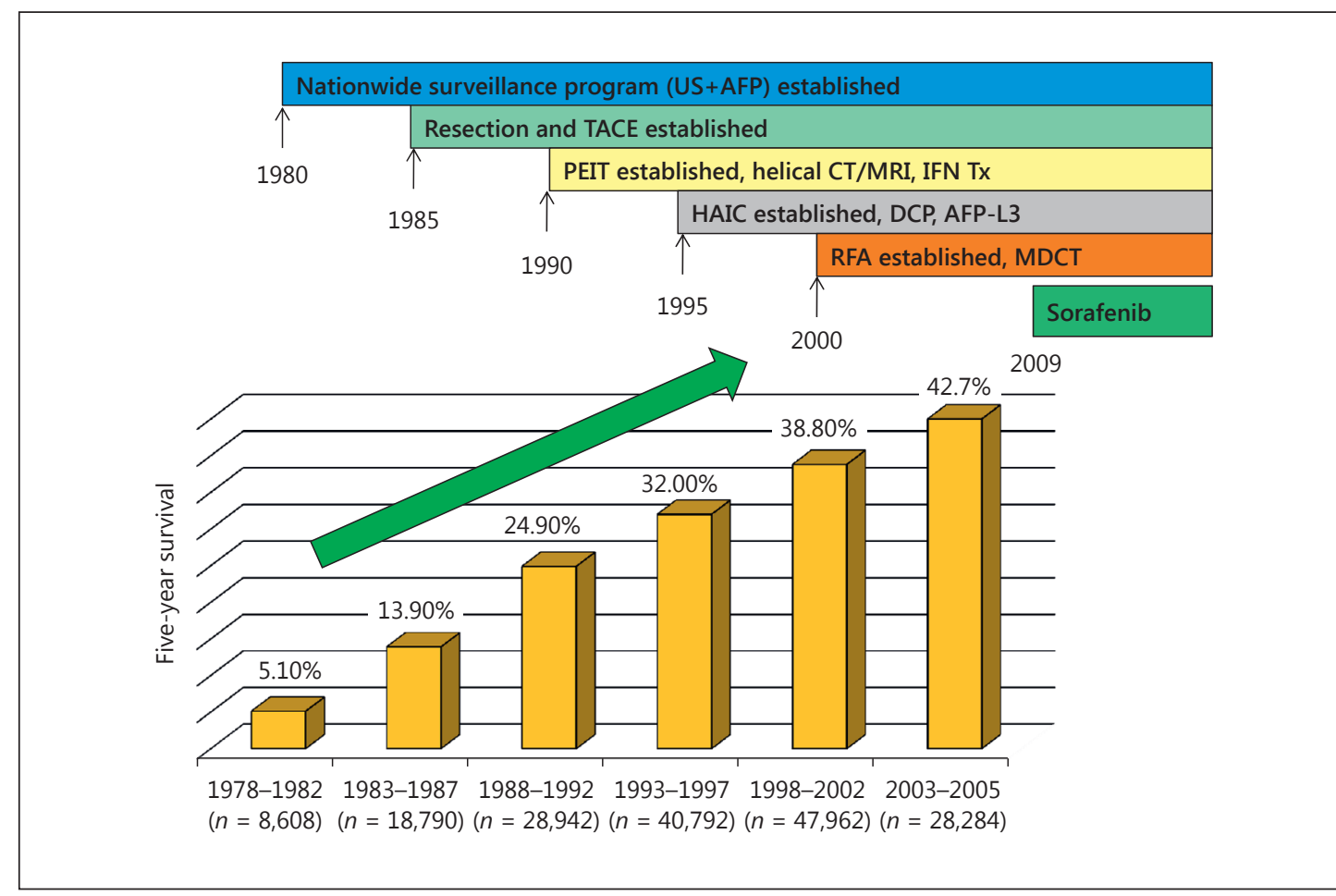

Fig. 3. Improvement of 5-year survival rate in patients with HCC. Results of the nationwide survey of the Liver Cancer Study Group of Japan $(n=173,378)$. MDCT, multidetector-row CT; PEIT, percutaneous ethanol injection therapy; IFN Tx, interferon treatment; DCP, des- $\gamma$-carboxy protein.

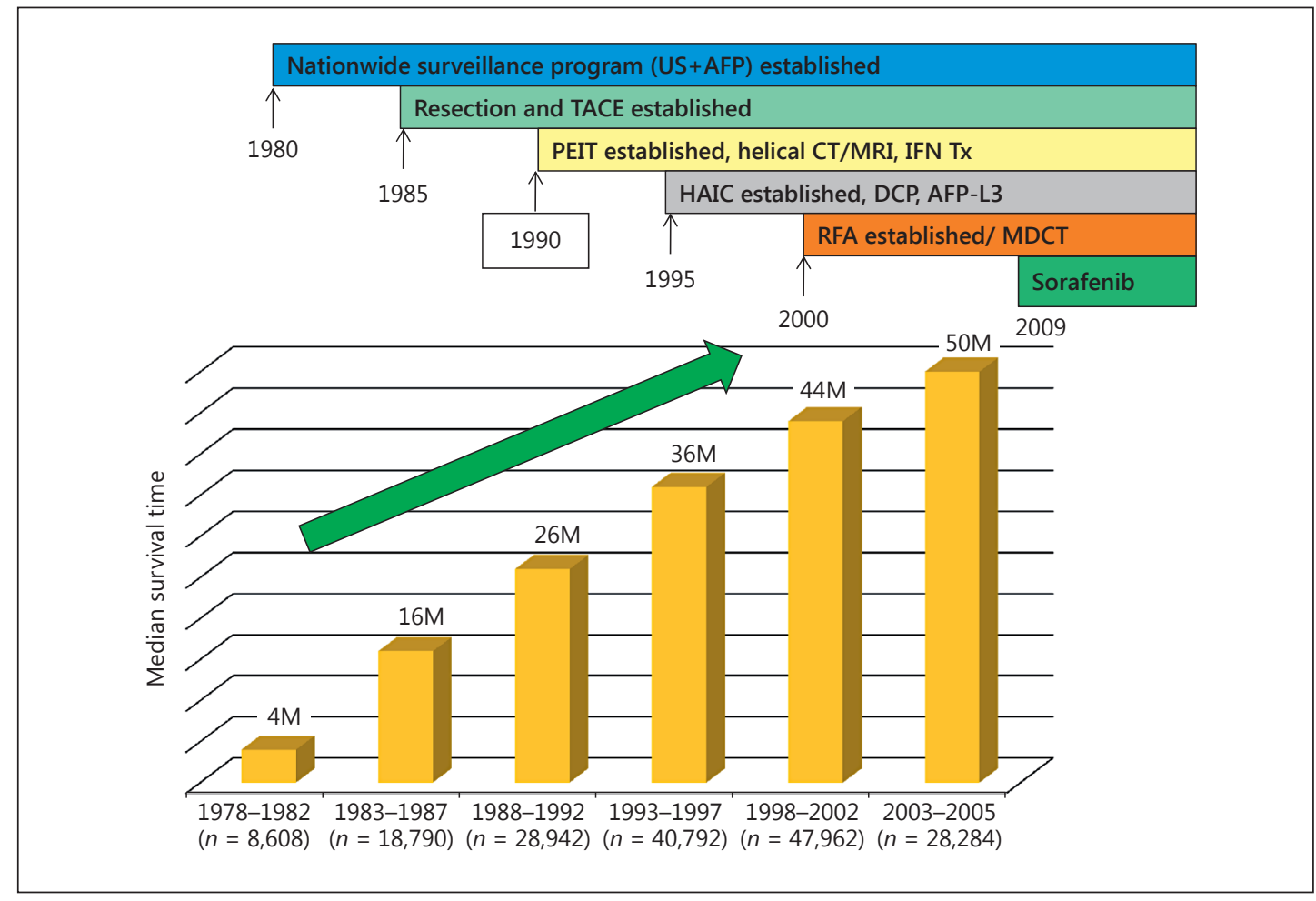

Fig. 4. Improvement of overall survival in patients with HCC. Results of the nationwide survey of the Liver Cancer Study Group of Japan $(n=173,378)$. M, months. For further abbreviations, see Figure 3. 


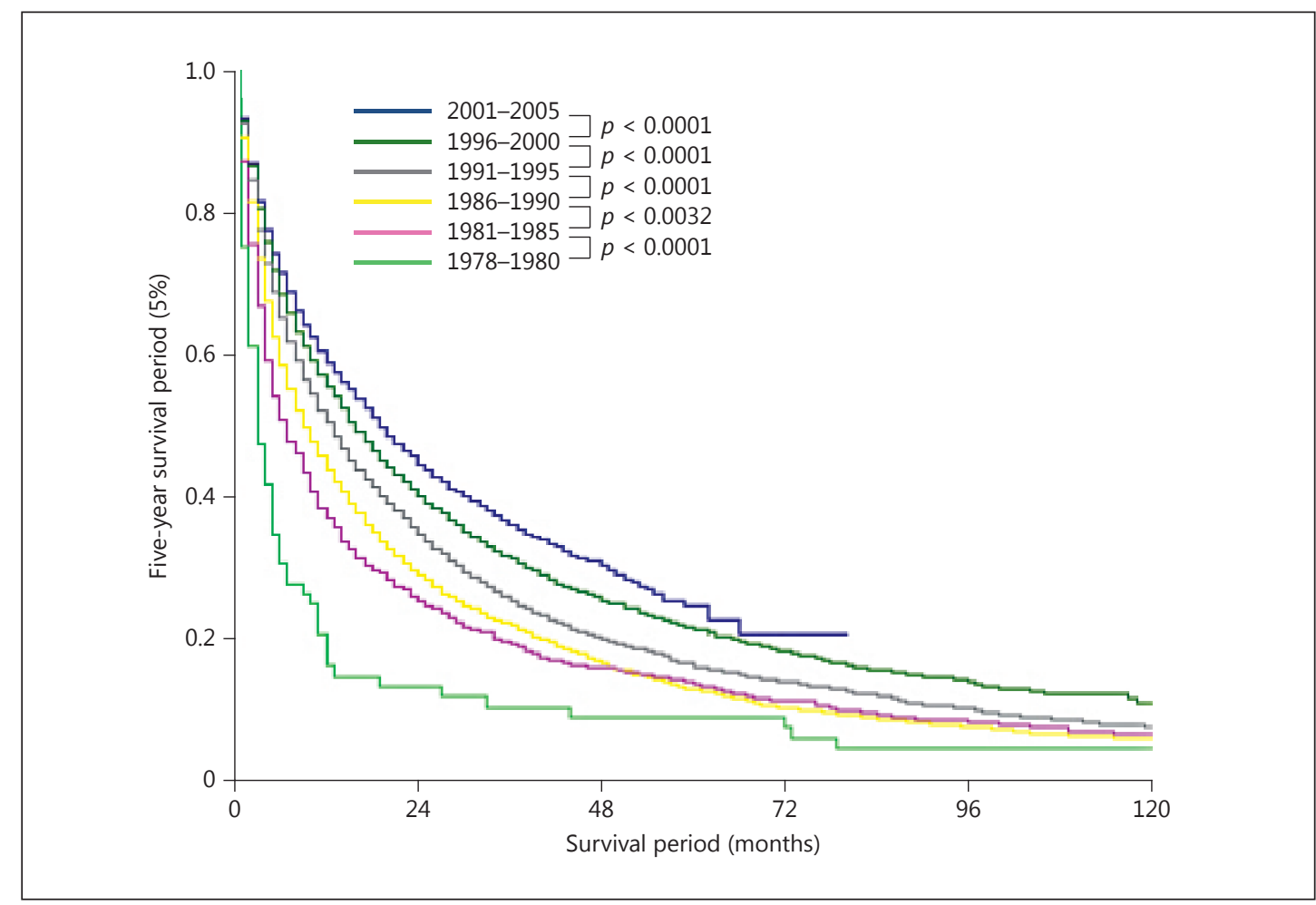

Fig. 5. Improvement of treatment outcome in HCC patients with AFP value $\geq 400 \mathrm{ng} / \mathrm{mL}$.

the 5-year survival rate was 5.1\%, and it gradually improved to $42.7 \%$ between 2003 and 2005. This increase was buoyed by rapid advances in diagnostic imaging technologies, the development of three tumor markers (AFP, PIVKA-II, and AFP-L3) with health insurance coverage, technological advances in surgery, and the development of local ablation therapy, TACE, and hepatic arterial infusion chemotherapy (HAIC) (Fig. 3). Similarly, the median survival time improved steadily from 4 months in the period of 1978-1982 to 50 months in the period of 2003-2005 (Fig. 4). These improvements were attributed to the establishment of the screening system, advances in diagnostic imaging enabling early detection of small tumors, and advanced therapeutic technologies. Indeed, assessment of the outcomes of resection, ablation, TACE, and HAIC in patients at 5-year intervals over 28 years shows a steady improvement in all modalities [17]. Moreover, the treatment outcomes of patients with poor prognostic indicators (AFP level $\geq 400 \mathrm{ng} / \mathrm{mL}$ ) are also improving steadily (Fig. 5).

\section{Implications of the Results of the GIDEON Study}

A global prospective noninterventional observational study, GIDEON (global investigation of therapeutic decisions in HCC and of its treatment with sorafenib: NCT 00812175), examined HCC patients treated with sorafenib at 378 institutes in 39 countries (including 3,213 patients treated at 40 participating institutes in Japan). Subgroup analysis of a vast amount of GIDEON data detected regional differences in the characteristics of patients at the initial examination for HCC and in treatment outcomes according to BCLC stage in the AsiaPacific region $(n=955)$, Europe $(n=1,115)$, Latin America $(n=90)$, the United States $(n=$ 553), and Japan $(n=500)$ [18] (Table 4). 
Kudo et al.: Management of Hepatocellular Carcinoma in Japan as a World-Leading Model

Table 4. Median time from initial diagnosis to death (in months) by BCLC stage at initial diagnosis

\begin{tabular}{|c|c|c|c|c|c|c|}
\hline & $\begin{array}{l}\text { AP } \\
(n=955)\end{array}$ & $\begin{array}{l}\text { EU } \\
(n=1,115)\end{array}$ & $\begin{array}{l}\text { LA } \\
n=90\end{array}$ & $\begin{array}{l}\text { USA } \\
(n=553)\end{array}$ & $\begin{array}{l}\text { Japan } \\
(n=500)\end{array}$ & $\begin{array}{l}\text { Overall } \\
(n=3,213)^{\mathrm{a}}\end{array}$ \\
\hline $\begin{array}{c}\text { BCLC stage A } \\
\qquad(n=686)\end{array}$ & $\begin{array}{l}54.0 \\
(10.3-\mathrm{NA})\end{array}$ & $\begin{array}{l}49.3 \\
(42.3-58.0)\end{array}$ & $\begin{array}{l}23.3 \\
(17.2-\mathrm{NA})\end{array}$ & $\begin{array}{l}24.9 \\
(18.4-53.5)\end{array}$ & $\begin{array}{l}91.0 \\
(76.6-113.1)\end{array}$ & $\begin{array}{l}59.2 \\
(51.9-67.5)\end{array}$ \\
\hline $\begin{array}{c}\text { BCLC stage B } \\
\quad(n=633)\end{array}$ & $\begin{array}{l}31.0 \\
(18.4-47.7)\end{array}$ & $\begin{array}{l}27.3 \\
(23.0-33.1)\end{array}$ & $\begin{array}{l}22.2 \\
(12.9-\mathrm{NA})\end{array}$ & $\begin{array}{l}19.7 \\
(11.1-36.8)\end{array}$ & $\begin{array}{l}47.9 \\
(40.9-86.2)\end{array}$ & $\begin{array}{l}29.9 \\
(25.6-39.0)\end{array}$ \\
\hline $\begin{array}{r}\text { BCLC stage C } \\
\quad(n=973)\end{array}$ & $\begin{array}{l}10.3 \\
(8.6-14.8)\end{array}$ & $\begin{array}{l}11.0 \\
(8.9-13.0)\end{array}$ & $\begin{array}{l}11.2 \\
(3.1-\mathrm{NA})\end{array}$ & $\begin{array}{l}8.5 \\
(6.2-10.2)\end{array}$ & $\begin{array}{l}27.7 \\
(16.6-40.8)\end{array}$ & $\begin{array}{l}10.6 \\
(9.4-12.4)\end{array}$ \\
\hline $\begin{array}{c}\text { BCLC stage D } \\
\quad(n=91)\end{array}$ & $\begin{array}{l}8.9 \\
(8.6-14.8)\end{array}$ & $\begin{array}{l}11.0 \\
(4.2-21.7)\end{array}$ & NA & $\begin{array}{l}7.5 \\
(4.5-12.8)\end{array}$ & $\begin{array}{l}13.1 \\
\text { (NA-NA) }\end{array}$ & $\begin{array}{l}8.9 \\
(6.2-13.1)\end{array}$ \\
\hline Overall & $\begin{array}{l}20.9 \\
(17.3-25.2)\end{array}$ & $\begin{array}{l}25.0 \\
(22.9-28.7)\end{array}$ & $\begin{array}{l}19.5 \\
(13.5-\mathrm{NA})\end{array}$ & $\begin{array}{l}14.8 \\
(13.1-17.0)\end{array}$ & $\begin{array}{l}79.6 \\
(62.1-96.0)\end{array}$ & $\begin{array}{l}25.5 \\
(23.9-28.3)\end{array}$ \\
\hline
\end{tabular}

Figures in parentheses are 95\% CI. AP, Asia-Pacific region; LA, Latin America; NA, not available. ${ }^{\text {a Intention- }}$ to-treat population.

Notable regional differences were observed in the time between initial diagnosis and death. The median survival of HCC patients in Japan was 79.6 months, which was longer than that of patients in other regions (20.9 months in the Asia-Pacific region, 25.0 months in Europe, 19.5 months in Latin America, and 14.8 months in the United States). Although each BCLC stage group is expected to consist of homogeneous patients in terms of tumor burden and liver function, the median survival of patients with BCLC stage A HCC (curatively treatable early-stage disease) was 91.0 months in Japan, which is considerably longer than that in other regions (54.0 months in the Asia-Pacific region, 49.3 months in Europe, 23.3 months in Latin America, and 24.9 months in the United States) $[18,19]$.

Similarly, in patients with BCLC stage B HCC (multinodular disease with preserved hepatic functional reserve), the median survival was 47.9 months in Japan, which was markedly longer than that in other regions (31.0 months in the Asia-Pacific region, 27.3 months in Europe, 22.2 months in Latin America, and 19.7 months in the United States). In patients with BCLC stage C HCC (with vascular invasion and/or extrahepatic spread), the median survival was longer in Japan (27.7 months) than in other regions (8.5-11.2 months) (Table 4).

In patients with BCLC stage D HCC (terminal stage: hepatic functional reserve of ChildPugh C HCC) who would generally receive palliative treatment, the median survival was still the longest in Japan (13.1 months) compared with that in other regions (7.5-11.0 months) $[18,19]$.

Collectively, treatment outcomes were better in Japan than in any other regions in all BCLC stage categories (A-D), each of which is thought to have a homogeneous patient population. This can be explained by Japan's well-established nationwide screening system, which enables early detection of small tumors in many cases. Another reason is the accurate and comprehensive diagnostic imaging capabilities available in Japan, which facilitate the appropriate allocation of treatment strategies according to liver function and tumor burden/characteristics. The superior outcomes of patients with BCLC stage A HCC in Japan can be attributed to the technical superiority of resection and locoregional therapies. For example, indications for liver resection are based on stringent assessment of hepatic functional reserve, and in resectable cases, repeated resections are proactively performed even in cases of recurrence after first resection. 


\section{Liver
Cancer}

\begin{tabular}{l|l}
\hline Liver Cancer 2018;7:134-147 \\
\hline DOI: 10.1159/000484619 & $\begin{array}{l}\text { ( ) 2017 S. Karger AG, Basel } \\
\text { www.karger.com/lic }\end{array}$ \\
\hline $\begin{array}{l}\text { Kudo et al.: Management of Hepatocellular Carcinoma in Japan as a World-Leading } \\
\text { Model }\end{array}$
\end{tabular}

Similarly, a standard RFA procedure in Japan includes that post-RFA response evaluation is proactively performed using imaging technique such as MDCT, contrast-enhanced ultrasonography, or EOB-MRI on the same day immediately after RFA procedure or the day after RFA to confirm that a complete tumor necrosis with a sufficient ablative margin is achieved. If the margin is not satisfactory, RFA is repeated until an adequate ablative margin is obtained and complete response is achieved during a single hospital stay. The rate of complete response, either in theory or in practice, is therefore $100 \%$ in Japan. However, these procedures are different in Western countries. In Western countries, response evaluation CT is usually performed at approximately 1 month after RFA to assess the therapeutic effect, and intrahepatic microscopic spread originating from the residual tumor or local recurrence might occur during that period. So, achieving complete response at a single hospital stay is a key point to reduce local recurrence as well as intrahepatic spread.

In patients with intermediate-stage (BCLC stage B) HCC who would typically undergo TACE, the number and size of nodules tend to be smaller in Japan than in Western and other Asian countries because of the beneficial effects of early detection of HCC in Japan. Therefore, patients can be treated by superselective conventional TACE (CTACE) with iodized oil (Lipiodol ${ }^{\circledR}$ ). During this procedure, a catheter is inserted into a feeding artery in close proximity to the feeding artery of each multinodular tumor. The Lipiodol injection within the feeding artery close to the tumors causes reflux of Lipiodol from the hepatic artery into the portal branches through physiologic arterioportal communications in the peribiliary plexus, thereby temporarily blocking portal flow. The subsequent placement of a gelatin sponge at the arterial side blocks arterial and portal blood flow; the resulting transient liver infarction, albeit on a small scale, can cause complete necrosis of subcapsular viable lesions, extracapsular growth, and even microsatellite lesions, which would not be treated by arterial occlusion alone. Furthermore, superselective embolization minimizes the impairment of hepatic functional reserve, allowing repeated TACE and improving prognosis. Superselective cTACE, in addition to resection, liver transplantation, and ablation, is categorized into one of the curative treatment modalities for patients with HCC included in the up-to-seven criteria in Japan [20]. This technique is not widely used in Europe and North America; however, given that many intermediate-stage HCC patients in these regions present with numerous nodules $(\geq 10)$ in both lobes or with a large tumor, the superselective cTACE procedure cannot be applied.

The BCLC stage C population, comprising patients with advanced HCC characterized by vascular invasion and/or extrahepatic spread, is relatively homogeneous compared with BCLC stage $0, A$, and B populations; therefore, patients with the same stage disease are expected to have similar prognoses. Indeed, the median survival of these patients in Europe, Asia, Latin America, and the United States (8.5-11.2 months) is reasonable and similar to that in the sorafenib and placebo groups of the SHARP study. Why then does Japan have such an outstandingly better median survival (27.7 months)? According to Japanese guidelines [15], HCC specialists in Japan opt for resection for the treatment of HCC even in cases with vascular invasion, provided that tumor conditions and liver function meet the requirements in selected patients. Propensity score-matching analysis shows that vascular invasion-positive patients who undergo resection have a better prognosis than those treated with other modalities [21, 22]. Similarly, TACE is preferred over molecular-targeted therapy because of its strong necrotizing effect in many cases of HCC with minor vascular invasion (Vp1, 2) that meet liver function criteria. The benefits of TACE in patients with vascular invasion were demonstrated in a systematic review [23]. Another unique treatment approach for vascular invasion in Japan is HAIC. This modality has not been tested in a prospective study and is not globally recognized as a standard of care.

Although it is only performed in Japan, South Korea, and Taiwan, it showed beneficial effects in the selected HCC patients with vascular invasion [24]. Propensity score-matching 


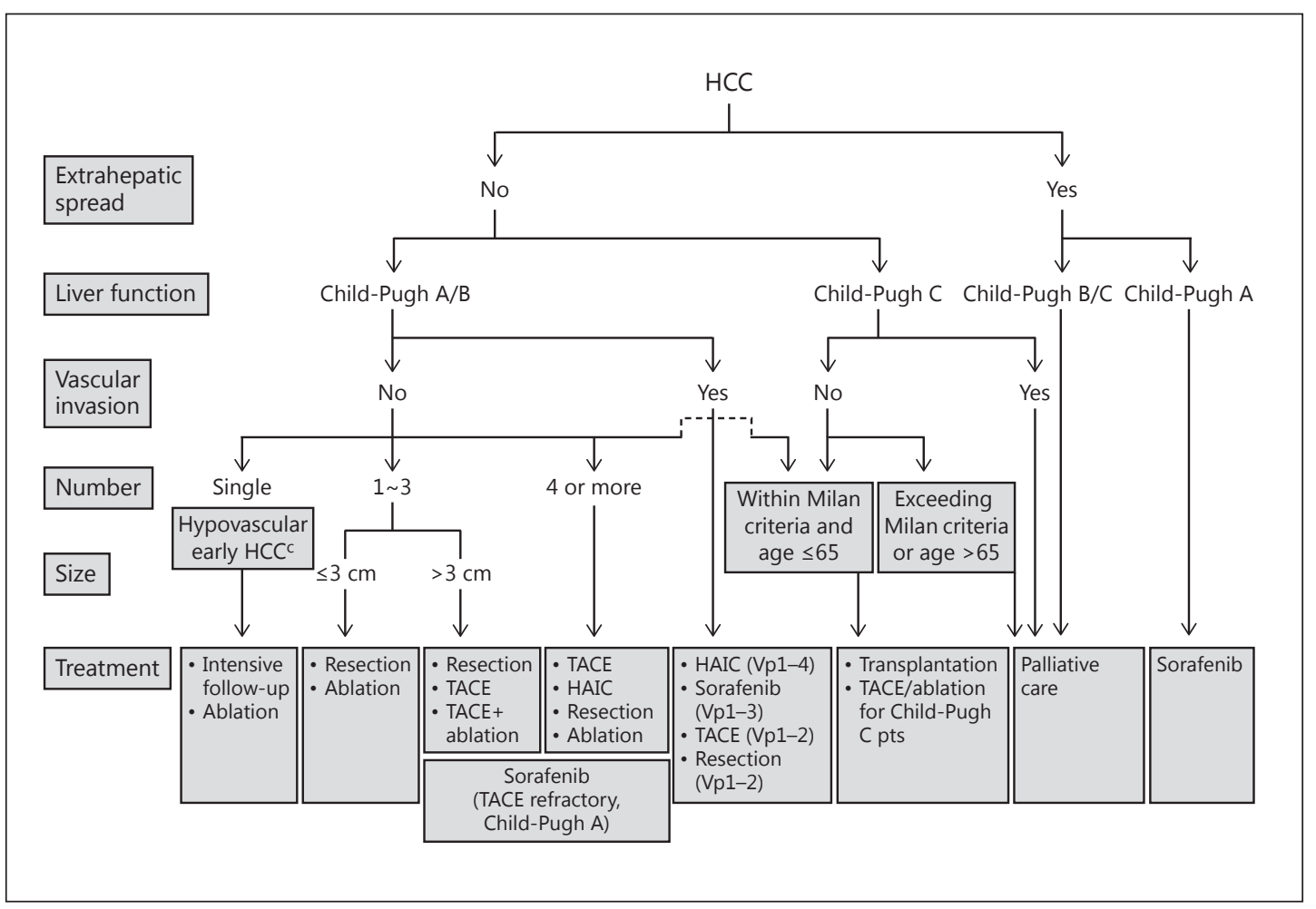

Fig. 6. The Japan Society of Hepatology consensus-based HCC treatment algorithm.

analysis of data collected through a nationwide follow-up survey of primary liver cancer by the Liver Cancer Study Group of Japan showed that patients with HCC with vascular invasion treated with HAIC had a better prognosis than those treated with other therapies [25]. As reported at the European Association for the Study of the Liver (EASL) International Liver Congress 2016, the SILIUS trial, which compared sorafenib alone with sorafenib plus HAIC in patients with a tumor thrombus in the main trunk of the portal vein $(\mathrm{Vp} 4$, a stratification factor), showed that additional HAIC extended median survival from 6.5 to 11.4 months (hazard ratio $=0.493,95 \%$ confidence interval $=0.240-1.014, p=0.050$ ) [26]. Given the typical survival of 2-3 months in Vp4 HCC patients [27], these results suggest that HAIC provides additional clinically meaningful benefits to the moderate survival extension by sorafenib alone. Taken together, resection, TACE, and HAIC, in addition to molecular-targeted therapy, are more readily used in the treatment of HCC with vascular invasion in Japan, albeit in selected cases only, than in other regions, which may prolong overall survival in BCLC C HCC patients. Moreover, because intrahepatic lesions are a strong prognostic factor in HCC, even in cases with extrahepatic spread [23], locoregional therapy, such as TACE and HAIC, is frequently performed in these patients, and this may contribute to the favorable treatment outcomes of patients with advanced HCC in Japan. Indeed, a trial of second-line S-1 versus placebo in HCC patients refractory or intolerant to sorafenib conducted only in Japan (S-CUBE trial) showed a survival of 11.3 months in the placebo arm [28], which was longer than the survival times in similar placebo groups in other second-line trials conducted globally (BRISK-PS, 8.2 months; EVOLVE-1, 7.3 months; and REACH,7.6 months) [29-31]. Furthermore, compared with first-line trials conducted globally, the placebo arm in the S-CUBE trial showed the longest survival, even in comparison with the survival of patients treated with sorafenib (SUN1170, 10.2 months; BRISK-FL, 9.9 months; and LiGHT, 9.8 months) [32-34]. It is likely 


\section{Liver}

\begin{tabular}{l|l}
\hline Liver Cancer 2018;7:134-147 \\
\hline DOI: 10.1159/000484619 & $\begin{array}{l}\text { C 2017 S. Karger AG, Basel } \\
\text { www.karger.com/lic }\end{array}$ \\
\hline
\end{tabular}

Kudo et al.: Management of Hepatocellular Carcinoma in Japan as a World-Leading Model

Table 5. Overall survival of HCC by country

\begin{tabular}{lll}
\hline Country & Period & 5-year overall survival, \% \\
\hline Japan [40] & $1998-2007$ & 44.1 \\
Korea $^{\text {a }}$ & $2004-2008$ & 23.3 \\
Taiwan $^{\text {b }}$ & $2010-2013$ & 22 \\
United States [41-44] $^{2}$ & $1992-2008$ & $11-15$ \\
\hline
\end{tabular}

a Ministry of Health \& Welfare, The Korean Cancer Registry, 2010. ${ }^{b}$ Cancer Registry, Taiwan 2001-2005.

that as the clinical practice guidelines in Japan recommend resection, TACE, and HAIC for the patients with advanced HCC (Fig. 6), these proactive strategies may result in a considerable improvement in the survival of patients with advanced HCC.

The survival of patients with end-stage HCC (BCLC stage D or Child-Pugh class C) is also longer in Japan than in other countries. A follow-up survey by the Liver Cancer Study Group of Japan revealed that approximately half of Child-Pugh class C HCC patients in Japan receive locoregional therapy (resection, ablation, and TACE, or HAIC). Propensity score-matching analysis of data from this follow-up survey showed that local ablation therapies and TACE improve survival in patients with a Child-Pugh score of 10 or 11 [35], consistent with other multicenter or single-center studies [36-39]. In Japan, locoregional therapy is used in routine clinical practice for carefully selected patients with Child-Pugh C HCC within the Milan criteria, and TACE and ablation appear to be beneficial in such patients. This is why the consensusbased clinical practice guidelines of the Japan Society of Hepatology include TACE and ablation as treatment options for Child-Pugh C HCC patients after careful patient selection [15].

Analysis of data from the GIDEON study also showed that survival, even in BCLC stage D HCC patients, was better in Japan than in other regions, reflecting the unique clinical practice pattern for HCC management and the consequent favorable treatment outcomes in Japan.

\section{Comparison of the Outcomes of HCC Treatments among Countries}

Only a few countries publish nationwide HCC treatment outcomes. The 5-year survival rate of all HCCs in Japan is 44.1\% [40], which is outstanding compared with the rates in other countries that published in the corresponding period $(23.3 \%$ in South Korea, 22\% in Taiwan, and $11-15 \%$ in the United States) [41-44] (Table 5).

\section{Total Number of Deaths from HCC in Japan}

The total number of deaths from HCC peaked in 2004 (34,510 deaths), and then gradually decreased to a number lower than that of deaths from pancreatic cancer in 2013 (30,175 vs. 30,672 deaths). This trend continued in 2014 and 2015, and the number of HCC deaths fell below 30,000 (28,889 deaths) in 2015 (Fig. 7). Early detection of HCC by established surveillance programs and the resulting high rate of opportunities for receiving curative treatment are clear contributing factors. Another likely reason is that most hepatitis B patients are treated with a nucleoside or nucleotide analogue. Disease progression to HCC is inhibited and liver function is preserved even after progression to HCC in these patients, which increases the therapeutic options and opportunities for repeated treatment. Similarly, the eradication of the hepatitis $C$ virus by interferon-based therapy and interferon-free direct-acting anti- 


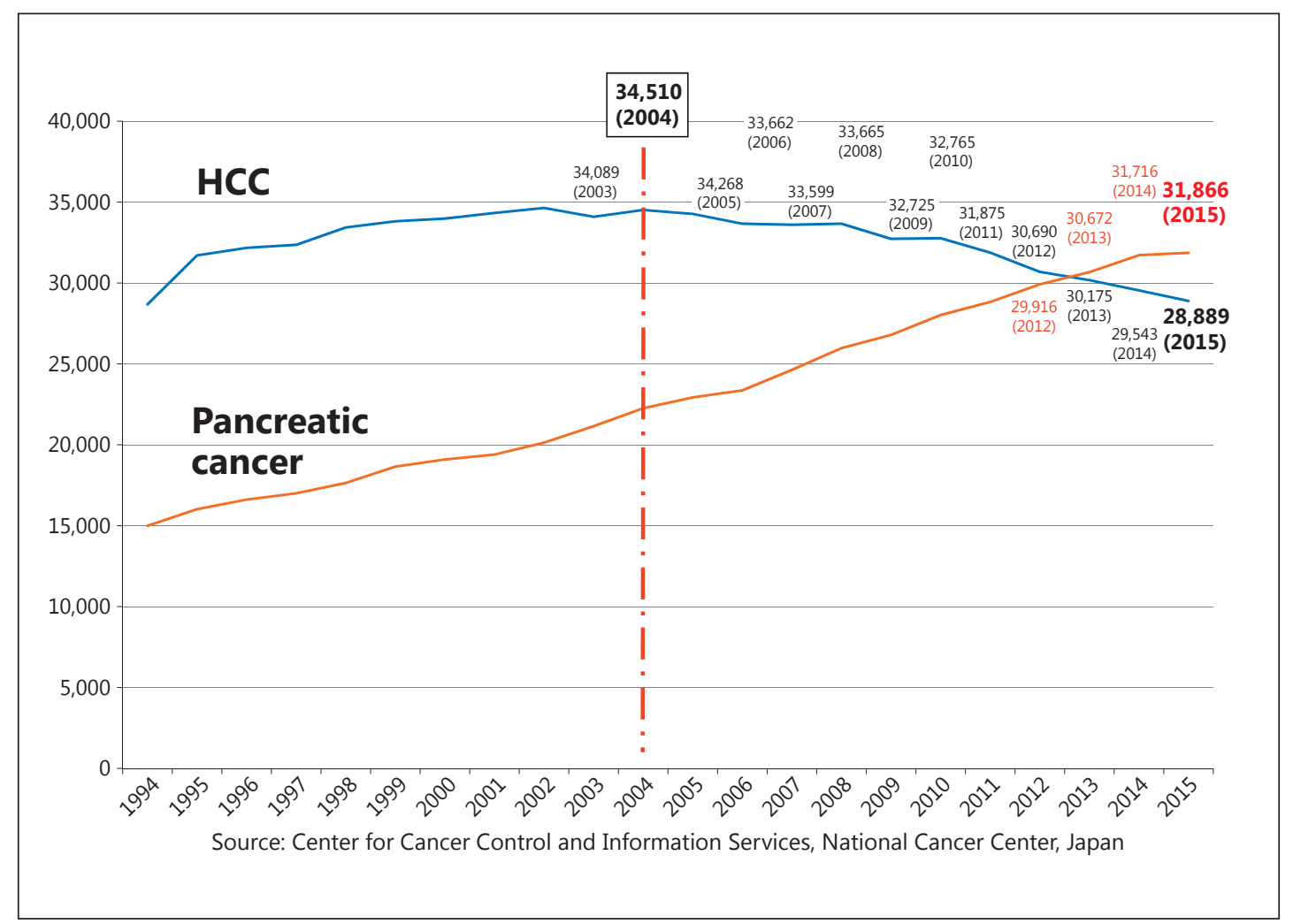

Fig. 7. Trend in HCC mortality in Japan.

virals contributes to suppressing the incidence of HCC. In addition, viral eradication, which is defined by a sustained virologic response, is likely to play a crucial role in inhibiting recurrence and maintaining hepatic functional reserve after curative treatment for HCC. Furthermore, the inclusion of the hepatitis B vaccine in the vaccination program for newborns in 1986 undoubtedly had some impact.

\section{Conclusion}

Japan leads the world in HCC treatment outcomes, which can be attributed to numerous achievements by Japanese pioneers in HCC treatment, the establishment of a nationwide surveillance system, precise diagnosis (confirmation, staging, use of contrast-enhanced ultrasound and EOB-MRI, and highly precise pathological diagnosis), and sophisticated treatment strategies (anatomic liver resection, contrast-enhanced ultrasound-assisted or fusion imaging-assisted RFA, RFA techniques that achieve adequate ablation margins, the proactive use of superselective cTACE, and intra-arterial infusion chemotherapy). In this respect, Japan is undoubtedly a suitable model for the world in HCC management [16]. The prognosis of liver cancer patients in Japan will improve further continuously, when additional moleculartargeted agents such as regorafenib [45] or lenvatinib [46], or even immunotherapy [47], become available in clinical practice for the treatment of HCC. 
Kudo et al.: Management of Hepatocellular Carcinoma in Japan as a World-Leading Model

\section{References}

1 Yamada R, Sato M, Kawabata M, Nakatsuka H, Nakamura K, Takashima S: Hepatic artery embolization in 120 patients with unresectable hepatoma. Radiology 1983;148:397-401.

2 Kudo M, Vera DR, Trudeau WL, Stadalnik RC: Validation of in vivo receptor measurements via in vitro radioassay: technetium-99m-galactosyl-neoglycoalbumin as prototype model. J Nucl Med 1991;32:1177-1182.

3 Kudo M, Todo A, Ikekubo K, Yamamoto K, Vera DR, Stadalnik RC: Quantitative assessment of hepatocellular function through in vivo radioreceptor imaging with technetium $99 \mathrm{~m}$ galactosyl human serum albumin. Hepatology 1993;17:814-819.

4 Honjo I, Araki C: Total resection of the right lobe of the liver; report of a successful case. J Int Coll Surg 1955; 23:23-28.

5 Makuuchi M, Hasegawa H, Yamazaki S: Ultrasonically guided subsegmentectomy. Surg Gynecol Obstet 1985; 161:346-350.

6 Sugiura NTK, Ohto M, et al: Ultrasound image-guided percutaneous intratumor ethanol injection for small hepatocellular carcinoma. Acta Hepatol Jpn 1983;24:920.

7 Seki T, Wakabayashi M, Nakagawa T, Itho T, Shiro T, Kunieda K, Sato M, Uchiyama S, Inoue K: Ultrasonically guided percutaneous microwave coagulation therapy for small hepatocellular carcinoma. Cancer 1994;74: 817-825.

8 Kudo M, Tomita S, Tochio H, Mimura J, Okabe Y, Kashida H, Hirasa M, Ibuki Y, Todo A: Sonography with intraarterial infusion of carbon dioxide microbubbles (sonographic angiography): value in differential diagnosis of hepatic tumors. AJR Am J Roentgenol 1992;158:65-74.

9 Kudo M, Tomita S, Tochio H, Mimura J, Okabe Y, Kashida H, Hirasa M, Ibuki Y, Todo A: Small hepatocellular carcinoma: diagnosis with US angiography with intraarterial $\mathrm{CO}_{2}$ microbubbles. Radiology 1992;182:155160.

10 Kudo M: Defect reperfusion imaging with Sonazoid ${ }^{\circledR}$ : a breakthrough in hepatocellular carcinoma. Liver Cancer 2016;5:1-7.

11 Ishida Y, Agata Y, Shibahara K, Honjo T: Induced expression of PD-1, a novel member of the immunoglobulin gene superfamily, upon programmed cell death. EMBO J 1992;11:3887-3895.

12 Cheng A, Finn R, Qin S, et al: Phase III trial of lenvatinib (LEN) vs sorafenib (SOR) in first-line treatment of patients (pts) with unresectable hepatocellular carcinoma (uHCC). J Clin Oncol 2017;35(suppl;abstr 4001).

13 Kudo M, Finn RS, Qin S, Han KH, Ikeda K, Piscaglia F, Baron AD, Park JW, Han G, Jassem J, Blanc JF, Vogel A, Komov D, Evans TJ, Lopez C, Dutcus C, Guo M, Saito K, Kraljevic S, Tamai T, Ren M, Cheng AL: A randomised phase 3 trial of lenvatinib vs. sorafenib in first-line treatment of patients with unresectable hepatocellular carcinoma. Lancet 2017, in press.

14 Kokudo N, Hasegawa K, Akahane M, Igaki H, Izumi N, Ichida T, Uemoto S, Kaneko S, Kawasaki S, Ku Y, Kudo M, Kubo S, Takayama T, Tateishi R, Fukuda T, Matsui O, Matsuyama Y, Murakami T, Arii S, Okazaki M, Makuuchi M: Evidence-Based Clinical Practice Guidelines for Hepatocellular Carcinoma: the Japan Society of Hepatology 2013 update (3rd JSH-HCC Guidelines). Hepatol Res 2015;45, DOI: 10.1111/hepr.12464.

15 Kudo M, Matsui O, Izumi N, Iijima H, Kadoya M, Imai Y, Okusaka T, Miyayama S, Tsuchiya K, Ueshima K, Hiraoka A, Ikeda M, Ogasawara S, Yamashita T, Minami T, Yamakado K: JSH consensus-based clinical practice guidelines for the management of hepatocellular carcinoma: 2014 update by the Liver Cancer Study Group of Japan. Liver Cancer 2014;3:458-468.

16 Kudo M: Japan's successful model of nationwide hepatocellular carcinoma surveillance highlighting the urgent need for global surveillance. Liver Cancer 2012;1:141-143.

17 Kudo M, Izumi N, Sakamoto M, Matsuyama Y, Ichida T, Nakashima O, Matsui O, Ku Y, Kokudo N, Makuuchi M: Survival analysis over 28 years of 173,378 patients with hepatocellular carcinoma in Japan. Liver Cancer 2016;5:190-197.

18 Kudo M, Lencioni R, Marrero JA, Venook AP, Bronowicki JP, Chen XP, Dagher L, Furuse J, Geschwind JF, Ladron de Guevara L, Papandreou C, Sanyal AJ, Takayama T, Yoon SK, Nakajima K, Lehr R, Heldner S, Ye SL: Regional differences in sorafenib-treated patients with hepatocellular carcinoma: GIDEON observational study. Liver Int 2016;36:1196-1205.

19 Kudo M, Ikeda M, Takayama T, Numata K, Izumi N, Furuse J, Okusaka T, Kadoya M, Yamashita S, Ito Y, Kokudo $\mathrm{N}$ : Safety and efficacy of sorafenib in Japanese patients with hepatocellular carcinoma in clinical practice: a subgroup analysis of GIDEON. J Gastroenterol 2016;51:1150-1160.

20 Kudo M, Arizumi T, Ueshima K, Sakurai T, Kitano M, Nishida N: Subclassification of BCLC B stage hepatocellular carcinoma and treatment strategies: proposal of modified Bolondi's subclassification (Kinki criteria). Dig Dis 2015;33:751-758.

21 Kokudo T, Hasegawa K, Matsuyama Y, Takayama T, Izumi N, Kadoya M, Kudo M, Ku Y, Sakamoto M, Nakashima 0, Kaneko S, Kokudo N: Survival benefit of liver resection for hepatocellular carcinoma associated with portal vein invasion. J Hepatol 2016;65:938-943.

22 Kokudo T, Hasegawa K, Matsuyama Y, Takayama T, Izumi N, Kadoya M, Kudo M, Kubo S, Sakamoto M, Nakashima 0, Kumada T, Kokudo N: Liver resection for hepatocellular carcinoma associated with hepatic vein invasion: a Japanese nationwide survey. Hepatology 2017;66:510-517. 
23 Zhao Y, Cai G, Zhou L, Liu L, Qi X, Bai M, Li Y, Fan D, Han G: Transarterial chemoembolization in hepatocellular carcinoma with vascular invasion or extrahepatic metastasis: a systematic review. Asia Pac J Clin Oncol 2013; 9:357-364.

24 Obi S, Yoshida H, Toune R, Unuma T, Kanda M, Sato S, Tateishi R, Teratani T, Shiina S, Omata M: Combination therapy of intraarterial 5 -fluorouracil and systemic interferon-alpha for advanced hepatocellular carcinoma with portal venous invasion. Cancer 2006;106:1990-1997.

25 Nouso K, Miyahara K, Uchida D, Kuwaki K, Izumi N, Omata M, Ichida T, Kudo M, Ku Y, Kokudo N, Sakamoto M, Nakashima O, Takayama T, Matsui O, Matsuyama Y, Yamamoto K: Effect of hepatic arterial infusion chemotherapy of 5-fluorouracil and cisplatin for advanced hepatocellular carcinoma in the Nationwide Survey of Primary Liver Cancer in Japan. Br J Cancer 2013;109:1904-1907.

26 Kudo M, Ueshima K, Yokosuka O, Obi S, Izumi N, Aikata H, Nagano H, Hatano E, Sasaki Y, Hino K, Kumada T, Yamamoto K, Imai Y, Iwadou S, Ogawa C, Okusaka T, Arai Y, Kanai F, Akazawa K, SILIUS Study Group: Prospective randomized controlled phase III trial comparing the efficacy of sorafenib versus sorafenib in combination with low-dose cisplatin/fluorouracil hepatic arterial infusion chemotherapy in patients with advanced hepatocellular carcinoma. J Hepatol 2016;64:S209-S210.

27 Chung GE, Lee JH, Kim HY, Hwang SY, Kim JS, Chung JW, Yoon JH, Lee HS, Kim YJ: Transarterial chemoembolization can be safely performed in patients with hepatocellular carcinoma invading the main portal vein and may improve the overall survival. Radiology 2011;258:627-634.

28 Kudo M, Moriguchi M, Numata K, Hidaka H, Tanaka H, Ikeda M, Kawazoe S, Ohkawa S, Sato Y, Kaneko S, Furuse J, Takeuchi M, Fang X, Date Y, Takeuchi M, Okusaka T: S-1 versus placebo in patients with sorafenib-refractory advanced hepatocellular carcinoma (S-CUBE): a randomised, double-blind, multicentre, phase 3 trial. Lancet Gastroenterol Hepatol 2017;2:407-417.

29 Llovet JM, Decaens T, Raoul JL, Boucher E, Kudo M, Chang C, Kang YK, Assenat E, Lim HY, Boige V, Mathurin P, Fartoux L, Lin DY, Bruix J, Poon RT, Sherman M, Blanc JF, Finn RS, Tak WY, Chao Y, Ezzeddine R, Liu D, Walters I, Park JW: Brivanib in patients with advanced hepatocellular carcinoma who were intolerant to sorafenib or for whom sorafenib failed: results from the randomized phase III BRISK-PS study. J Clin Oncol 2013;31:35093516.

30 Zhu AX, Kudo M, Assenat E, Cattan S, Kang YK, Lim HY, Poon RT, Blanc JF, Vogel A, Chen CL, Dorval E, PeckRadosavljevic M, Santoro A, Daniele B, Furuse J, Jappe A, Perraud K, Anak O, Sellami DB, Chen LT: Effect of everolimus on survival in advanced hepatocellular carcinoma after failure of sorafenib: the EVOLVE-1 randomized clinical trial. JAMA 2014;312:57-67.

31 Zhu AX, Park JO, Ryoo BY, Yen CJ, Poon R, Pastorelli D, Blanc JF, Chung HC, Baron AD, Pfiffer TE, Okusaka T, Kubackova K, Trojan J, Sastre J, Chau I, Chang SC, Abada PB, Yang L, Schwartz JD, Kudo M: Ramucirumab versus placebo as second-line treatment in patients with advanced hepatocellular carcinoma following first-line therapy with sorafenib (REACH): a randomised, double-blind, multicentre, phase 3 trial. Lancet Oncol 2015; 16:859-870.

32 Cheng AL, Kang YK, Lin DY, Park JW, Kudo M, Qin S, Chung HC, Song X, Xu J, Poggi G, Omata M, Pitman Lowenthal S, Lanzalone S, Yang L, Lechuga MJ, Raymond E: Sunitinib versus sorafenib in advanced hepatocellular cancer: results of a randomized phase III trial. J Clin Oncol 2013;31:4067-4075.

33 Johnson PJ, Qin S, Park JW, Poon RT, Raoul JL, Philip PA, Hsu CH, Hu TH, Heo J, Xu J, Lu L, Chao Y, Boucher E, Han KH, Paik SW, Robles-Avina J, Kudo M, Yan L, Sobhonslidsuk A, Komov D, Decaens T, Tak WY, Jeng LB, Liu D, Ezzeddine R, Walters I, Cheng AL: Brivanib versus sorafenib as first-line therapy in patients with unresectable, advanced hepatocellular carcinoma: results from the randomized phase III BRISK-FL study. J Clin Oncol 2013;31:3517-3524.

34 Cainap C, Qin S, Huang WT, Chung IJ, Pan H, Cheng Y, Kudo M, Kang YK, Chen PJ, Toh HC, Gorbunova V, Eskens FA, Qian J, McKee MD, Ricker JL, Carlson DM, El-Nowiem S: Linifanib versus sorafenib in patients with advanced hepatocellular carcinoma: results of a randomized phase III trial. J Clin Oncol 2015;33:172-179.

35 Kitai S, Kudo M, Nishida N, Izumi N, Sakamoto M, Matsuyama Y, Ichida T, Nakashima O, Matsui O, Ku Y, Kokudo N, Makuuchi M, Liver Cancer Study Group of Japan: Survival benefit of locoregional treatment for hepatocellular carcinoma with advanced liver cirrhosis. Liver Cancer 2016;5:175-189.

36 Nishikawa H, Kita R, Kimura T, Ohara Y, Takeda H, Sakamoto A, Saito S, Nishijima N, Nasu A, Komekado H, Osaki Y: Clinical efficacy of non-transplant therapies in patients with hepatocellular carcinoma with ChildPugh C liver cirrhosis. Anticancer Res 2014;34:3039-3044.

37 Nouso K, Kokudo N, Tanaka M, Kuromatsu R, Nishikawa H, Toyoda H, Oishi N, Kuwaki K, Kusanaga M, Sakaguchi T, Morise Z, Kitai S, Kudo M: Treatment of hepatocellular carcinoma with Child-Pugh C cirrhosis. Oncology 2014;87(suppl 1):99-103.

38 Nouso K, Ito Y, Kuwaki K, Kobayashi Y, Nakamura S, Ohashi Y, Yamamoto K: Prognostic factors and treatment effects for hepatocellular carcinoma in Child C cirrhosis. Br J Cancer 2008;98:1161-1165.

39 Kudo M, Osaki Y, Matsunaga T, Kasugai H, Oka H, Seki T: Hepatocellular carcinoma in Child-Pugh C cirrhosis: prognostic factors and survival benefit of nontransplant treatments. Dig Dis 2013;31:490-498.

40 Kudo M, Izumi N, Ichida T, Ku Y, Kokudo N, Sakamoto M, Takayama T, Nakashima O, Matsui O, Matsuyama Y: Report of the 19th follow-up survey of primary liver cancer in Japan. Hepatol Res 2016;46:372-390.

41 Altekruse SF, McGlynn KA, Dickie LA, Kleiner DE: Hepatocellular carcinoma confirmation, treatment, and survival in surveillance, epidemiology, and end results registries, 1992-2008. Hepatology 2012;55:476-482. 
42 Ries LAG, Melbert D, Krapcho M, et al (eds): SEER Cancer Statistics Review, 1975-2005, National Cancer Institute, Bethesda, MD. seer.cancer.gov/csr/1975_2005/, seer.cancer.gov/csr/1975_2008/ (accessed February 27, 2012).

43 American Cancer Society: Cancer Facts and Figures 2012. https://www.cancer.org/research/cancer-factsstatistics/all-cancer-facts-figures/cancer-facts-figures-2012.html.

44 El-Serag HB: Hepatocellular carcinoma. N Engl J Med 2011;365:1118-1127.

45 Bruix J, Qin S, Merle P, Granito A, Huang YH, Bodoky G, Pracht M, Yokosuka O, Rosmorduc O, Breder V, Gerolami R, Masi G, Ross PJ, Song T, Bronowicki JP, Ollivier-Hourmand I, Kudo M, Cheng AL, Llovet JM, Finn RS, LeBerre MA, Baumhauer A, Meinhardt G, Han G: Regorafenib for patients with hepatocellular carcinoma who progressed on sorafenib treatment (RESORCE): a randomised, double-blind, placebo-controlled, phase 3 trial. Lancet 2017;389:56-66.

46 Kudo M, Finn RS, Qin S, Han KH, Ikeda K, Piscaglia F, Baron A, Park JW, Han G, Jassem J, Blanc JF, Vogel A, Komov D, Evans J, Lopez C, Dutcus C, Guo M, Saito K, Kraljevic S, Tamai T, Ren M, Cheng AL: A randomised Phase 3 trial of lenvatinib vs sorafenib in first-line treatment of patients with unresectable hepatocellular carcinoma. Lancet 2017, in press.

47 El-Khoueiry AB, Sangro B, Yau T, Crocenzi TS, Kudo M, Hsu C, Kim TY, Choo SP, Trojan J, Welling THR, Meyer T, Kang YK, Yeo W, Chopra A, Anderson J, Dela Cruz C, Lang L, Neely J, Tang H, Dastani HB, Melero I: Nivolumab in patients with advanced hepatocellular carcinoma (CheckMate 040): an open-label, non-comparative, phase 1/2 dose escalation and expansion trial. Lancet 2017;389:2492-2502. 